УДК 552.086

\title{
ВОЗМОЖНОСТИ ОПРЕДЕЛЕНИЯ ТИПА СМАЧИВАЕМОСТИ КОЛЛЕКТОРОВ ПО ДАННЫМ КАРОТАЖА ПРИ ОПТИМИЗАЦИИ СИСТЕМЫ ЗАВОДНЕНИЯ НЕФТЯНЫХ ПЛАСТОВ
}

\author{
Галкин Сергей Владиславович1, \\ doc_galkin@mail.ru
}

Кольчев Игорь Юрьевич1, igorek999@yandex.ru

\author{
Ракинцев Владимир Андреевич², \\ rakintsevv.a@mail.ru \\ 1 Пермский национальный исследовательский политехнический университет, \\ Россия, 614990, г. Пермь, Комсомольский пр., 29. \\ 2 Филиал ООО «ЛУкОЙЛ-Инжиниринг» «ПермНИПИнефть» в г. Перми, \\ Россия, 614015, г. Пермь, ул. Пермская, За.
}

\begin{abstract}
Актуальность. Смачиваемость нефтенасыщенных коллекторов в значительной степени влияет на технологические особенности разработки эксплуатационных объектов, прежде всего, на эфффективность заводнения нефтяных пластов. Возможности определения смачиваемости по данным геофизических исследований скважин позволяют учитывать данный показатель при геолого-технологическом моделировании разработки эксплуатационных объектов, в том числе при оптимизации заводнения нефртяных пластов. Данная задача решена для условий залежей терригенных нефртенасыщенных коллекторов на основе комплексирования методов определения пористости, бокового электрического каротажа и микробокового каротажа. В публикации представлены результаты и анализ динамики приемистости нагнетательных скважин для битуминозных, гидрофообизированных и гидрофильных коллекторов. Для участков с низкой приемистостью скважин предложены геологотехнические мероприятия по оптимизации системы заводнения нефтяных пластов.

Цель: оценить возможность достоверного определения смачиваемости нестенасыщенных терригенных коллекторов, провести сравнительный анализ влияния показателя смачиваемости коллекторов на эфффективность заводнения нефтянных пластов, для различных геологических условий предложить эффекттивные технологические условия разработки эксплуатационных объектов.

Объект: нефртенасыщенные коллекторы визейских нефртяных залежей Соликамской депрессии (Пермский край).

Методика: разработка методологии и определение типа смачиваемости и степени битумизации интервалов терригенных коллекторов по данным комплексирования гамма каротажа, бокового электрического каротажа и микробокового каротажа; анализ динамики приемистости нагнетательных скважин для различных выделенных типов смачиваемости.

Результаты. Авторами на основе разработанной методики получены схемы зональности развития гидрофообизации и битумизации нефртенасыщенных коллекторов для объекта Тл-Бб Уньвинского месторождения. Проведен анализ динамики работы нагнетательных скважин для условий битуминозного, гидрофобизированного и гидрофильного геологического разреза. Построены схемы зональности развития процессов гидрофробизации и битумизации коллекторов, с которыми связаны участки снижения приемистости нагнетательных скважин. Предложены геолого-технические мероприятия по оптимизации системы заводнения нефтяных пластов в коллекторах гидрофробно-битуминозного типа.
\end{abstract}

\section{Ключевые слова:}

Смачиваемость, гидрофообньй коллектор, битумизация, геофизические исследования скважин,

удельное электрическое сопротивление, боковой электрический каротаж, заводнение нефтяных пластов.

\section{Введение}

При эксплуатации нефтяных месторождений влияние смачиваемости поверхности горных пород на условия разработки является достаточно очевидным. Как правило, при разработке проектно-технологической документации смачиваемость оценивается исключительно на керновом материале, где апробировано множество методов (адсорбционные, Амотта и др.) [1-3]. При анализе на кернах структурного пространства гидрофобизированных коллекторов в последние годы активно используется метод рентгеновской томографии [4-6]. В работе [7] с помощью комплексирования методов электронной микроскопии и рентгеновской томографии рассмотрены возможности изучения смачиваемости в различных масштабах от нанометров до сантиметров. Вместе с тем керном всегда охарактеризована лишь незначительная доля интервалов геологического разреза, в результате чего показатели смачиваемости пород фактически не используются при геолого-технологическом моделировании нефтяных месторождений, в том числе и для Пермского региона [8-10].

Определение смачиваемости по данным геофизических исследований скважин (ГИС) позволит во всем объеме залежи охарактеризовать данный показатель и значительно повысить качество технологических решений при разработке нефтяных эксплуатационных объектов. Данная проблема рассмотрена на примере месторождений Пермского региона, для которого крупные открытия нефтяных запасов последних лет приурочены к визейским коллекторам (пласты Тл, Бб, Мл) территории Соликамской депрессии. На этих новых месторождениях (Ростовицкое, им. Сухарева и ряд других более мелких) в настоящее 
время формируется система заводнения пластов, которая может быть оптимизирована с учетом информации по смачиваемости коллекторов.

Анализ истории разработки месторождений Соликамской депрессии показывает, что на визейских объектах реализуется преимущественно внутриконтурное заводнение, причем в ряде случаев наблюдается низкая приемистость нагнетательных скважин и как следствие неудовлетворительная компенсация отобранных объемов нефти закачкой. Для ряда сопредельных территорий (Татарстан, Башкортостан) снижение продуктивности скважин связывается с битумизацией коллекторов. Битуминозные интервалы представлены песчаниками темного, часто до черного, окраса с низкой открытой пористостью $\left(K_{\Pi}\right)$.

Наиболее полно данные вопросы рассмотрены в работе [11], где процессы развития гидрофобизации коллекторов считаются вторичными во взаимосвязи с окислением нефтей на участках формирования древних водонефтяных контактов (ВНК) $[11,12]$. Анализ показывает, что эти процессы, как правило, приурочены к крупным структурным поднятиям, для которых в историческом времени наиболее вероятны процессы переформирования ВНК.

Степень битумизации коллекторов зависит от их фильтрационно-емкостных свойств (ФЕС). Малопроницаемые коллекторы в геологическом разрезе выделяются в виде темных битуминозных пластов. В интервалах с лучшими ФЕС за длительное геологическое время битумы вымываются из порового пространства, что приводит к осветлению пород, но не к восстановлению их начальной гидрофильности.

Обоснование критериев выделения гидрофобизированных и битуминозных коллекторов по данным геофизических исследований скважин

Электрический ток в нефтенасыщенных коллекторах движется по пустотам, занятым остаточной водой, поэтому для них условием низких удельных электрических сопротивлений (УЭС) является непрерывность распределения в пустотном пространстве водной фазы. Гидрофобизация пород ведет к нарушению непрерывности водной фазы, в результате чего УЭС резко возрастает. В работе [13] проведены эксперименты изменения смачиваемости образцов керна из одного и того же типа породы, в результате которых построена модель влияния смачиваемости на измерения УЭС. В целом, согласно известным расчетным формулам оценки УЭС $[14,15]$, показатель смачиваемости находится в их степенной части, что делает его влияние на показания УЭС определяющим. Аномально высокие показания УЭС в гидрофобных нефтенасыщенных коллекторах подтверждаются промысловыми данными для месторождений Татарстана [16], Пермского края [17], республики Коми [18] и других территорий.

Для Пермского края высокие УЭС встречены повсеместно. Однако юг территории активно разбуривался более 40 лет назад с применением стандартного электрического каротажа, для которого достоверное определение УЭС возможно для пропластков более 2 м.
Район Соликамской депрессии начал разбуриваться позднее (с конца 80-ых гг. ХХ в.) с применением бокового электрического каротажа (БК), который позволяет более надежно определять УЭС пород, в том числе для маломощных пропластков ( $\mathrm{h}>0,8$ м) [19-21].

Таким образом, для визейских терригенных коллекторов нефтяных месторождений Соликамской депрессии можно по данным БК провести районирование территории по типу их смачиваемости. В работах $[17,22]$ на основе сопоставления данных керна и БК для визейских коллекторов установлены закономерности влияния смачиваемости на УЭС пород. При анализе для изучения структурного пространства керна из различных интервалов разреза по УЭС дополнительно выполнялись анализ шлифов и исследования методом рентгеновской томографии. В результате сделаны выводы, что интервалы нефтенасыщенного разреза с УЭС $<120$ Ом'м гидрофильны, с УЭС $>200$ Ом·м начинают проявляться явные признаки гидрофобности, а при УЭС>600 Ом·м коллекторы гидрофобны [22].

Для анализа в данной работе дополнительно привлечены результаты микробокового каротажа (МБК). Низкие показания МБК характеризуют проникновение фильтрата бурового раствора в пласт, повышенные УЭС - отсутствие проникновения, что интерпретируется как следствие битумизации коллекторов.

На рис. 1 представлены примеры диаграмм БК и МБК для скважин Уньвинского месторождения нефти. Для скважины 486 интервал с отбором керна (глубина 2214 м) представлен высокопористым $\left(K_{п}=21,4 \%\right)$ светлым песчаником без следов битумизации. Данный интервал характеризуется низкими значениями по МБК - 18 Ом·м, и очень высокими по БК - 1000 Ом'м (рис. 1, $a$ ). Для скважины 45 интервал с отбором керна (глубина 2160 м) представлен мелкозернистым черным битуминозным песчаником с $\mathrm{K}_{\mathrm{n}}=13,5 \%$. Данный интервал характеризуется аномально высоким УЭС по МБК (600 Ом·м), по БК он также уверенно относится к высокоомному разрезу (рис. 1,6$)$.

В целом для Пермского региона присутствие в геологическом разрезе визейских отложений битуминозных интервалов установлено менее чем для $20 \%$ скважин. Для нефтяных визейских залежей Соликамской депрессии на выборке 66 образцов керна $(14$ с битумом и 52 без битума) развитие битумизации сопоставлено с петрофизическими исследованиями. В результате сделан вывод, что битумизация коллекторов не характерна для гидрофильных коллекторов с УЭС менее 60 Омм (13 из 14). При УЭС по МБК менее 10 Ом·м все образцы керна (18 из 18) оказались без битумов. По мере роста показаний МБК вероятность битумизации последовательно возрастает, и при МБК>200 Ом·м все образцы (3 из 3) битуминозны. При этом битумизация коллекторов практически исключается при $\mathrm{K}_{\text {п }}>16$ \% (30 из 31), наиболее вероятна при $K_{п}<12$ \% (3 из 4). При отсутствии исследований методами БК и МБК с определенной долей погрешности граничным значением, разделяющим интервалы на битуминозные и нет, может рассматриваться $\mathrm{K}_{\mathrm{n}}=14 \%$. 


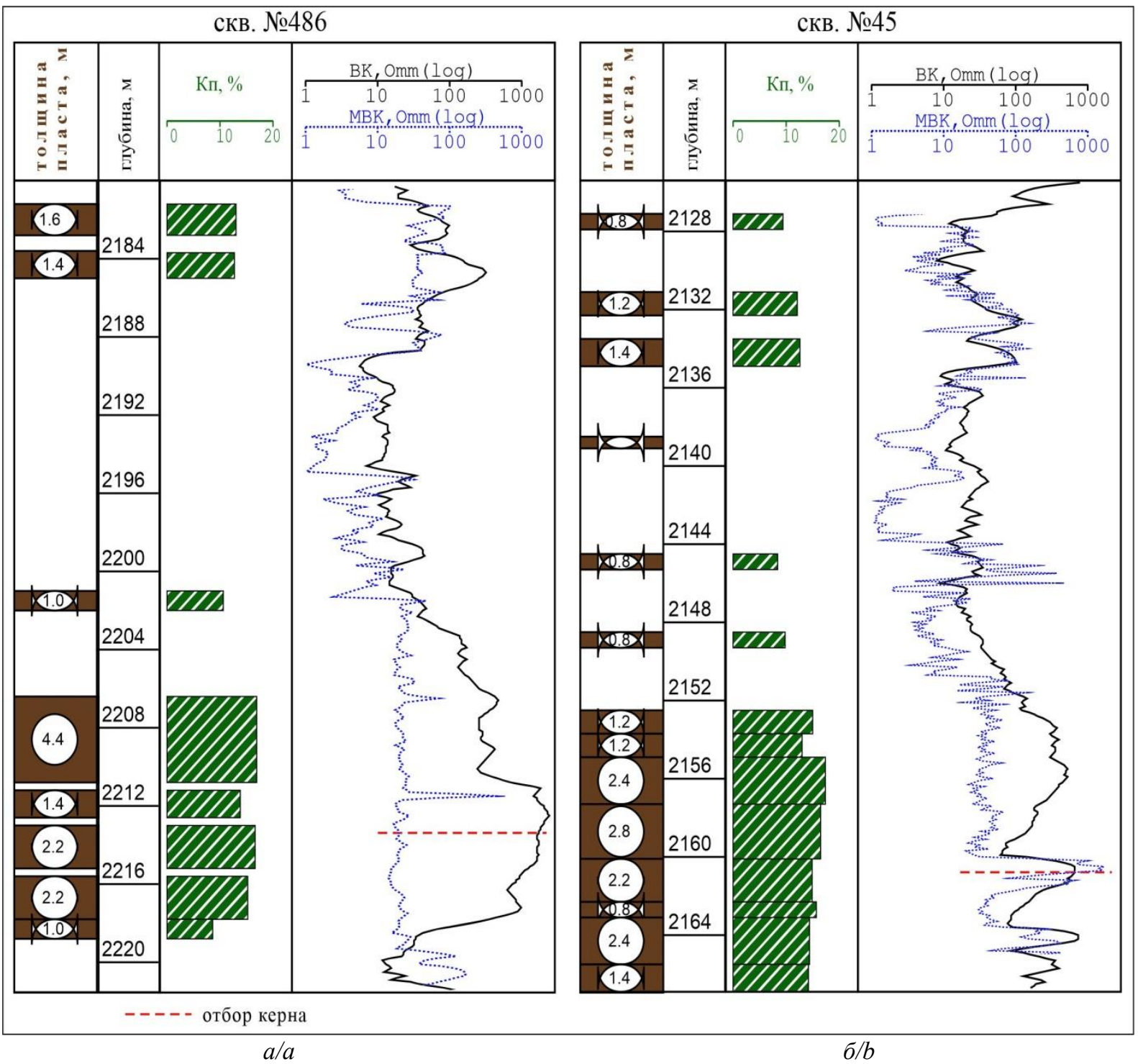

Pис. 1. Диаграммы методов электрического бокового и микробокового каротажа для продуктивных пластов 6 скважинах 486 (а) и 45 (б) Уньвинского месторождения нефти

Fig. 1. Diagrams of electrical lateral and micro-lateral logging methods for productive formations in wells 486 (a) and 45 (b) of the Unvinskoe oil field

При классификации по выработанным критериям 51 интервала обучающей выборки с полным комплексом методов (К тервалов; с неопределенной оценкой - 1; неверно оценены 2 битумизированных интервала. Ошибка прогноза типа смачиваемости при этом составляет 4 \%.

При классификации 66 интервалов с комплексом методов $K_{\text {п }}$ и БК (отсутствии данных по МБК) верно классифицируются 58 интервалов; с неопределенной оценкой - 1; неверно оценены 7 интервалов. Ошибка прогноза в данном случае увеличивается до $11 \%$.

\section{Построение схемы распространения коллекторов с различным типом смачиваемости и битумизации для коллекторов Уньвинского месторождения}

Приведенные выше принципы оценки гидрофобизации и битуминозности применены для визейских коллекторов Уньвинского месторождения, для которого самостоятельными объектами разработки явля- ются Уньвинское (на юго-западе), Юго-Восточное и Палашерское (на севере) поднятия. На месторождении с применением системы поддержания пластового давления (ППД) ведется совместная эксплуатация тульских и бобриковских терригенных коллекторов (объект Тл-Бб). По данным керна и ГИС более половины значений $\mathrm{K}_{\text {п }}$ распределяются в диапазоне от 13 до $18 \%$, причем в интервалы менее $8 \%$ и более $25 \%$ попадает малая доля интервалов [23], что, по классификации А.А. Ханина, соответствует средним значениям ФЕС.

Для скважин Уньвинского месторождения рассчитана доля гидрофобизации коллекторов (Д фоб) как отношение суммарных толщин с гидрофобизацией коллекторов к общей нефтенасыщенной толщине (от 0 до 1 д.е.). На рис. 2 приведена полученная в результате схема распространения степени гидрофобизации коллекторов. Светлый цвет на схеме соответствует участкам отсутствия гидрофобизации (Д фоб от 0 до 
0,2 д.е.), наиболее темный - максимальной гидрофобизации коллекторов (Дфоб от 0,8 до 1 д.е.).

Из рис. 2 видно, что на площади Уньвинского месторождения выделяются крупные зоны развития как гидрофильных, так и гидрофобных коллекторов, что подтверждает связь данного процесса, прежде всего, с геолого-тектоническими факторами. Коллекторы на Уньвинском поднятии в нефтеносной части преимущественно характеризуются высокоомным разрезом, ввиду чего практически вся площадь отнесена при прогнозе к гидрофобизированным участкам. В наименьшей степени процессы гидрофобизации проявляются для восточной части Палашерского и для Юго-Восточного поднятий.

Результаты анализа кернов Уньвинского месторождения показывают, что битумы встречены в половине исследованных интервалов (9 из 18). В результате расчета доли битумизированных коллекторов в общей нефтенасыщенной толщине (Дбит) построена схема битумизации коллекторов (рис. 3).

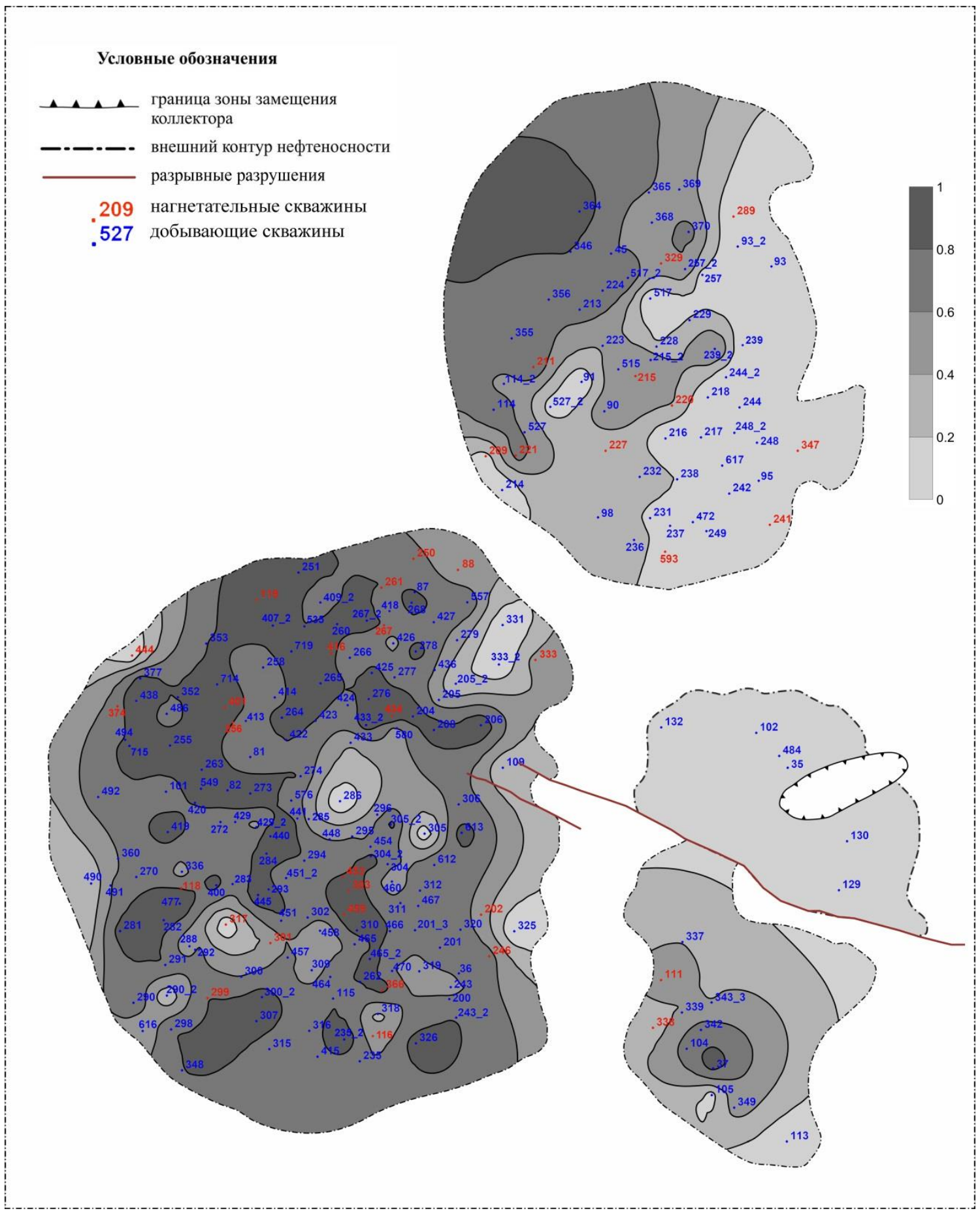

Pис. 2. Схема распространения доли гидрофобизированных коллекторов для эксплуатационного объекта Тл-Бб Уньвинского месторождения

Fig. 2. Scheme of distribution of the share of hydrophobized reservoirs for the Tl-Bb production facility of the Unvinskoe field 


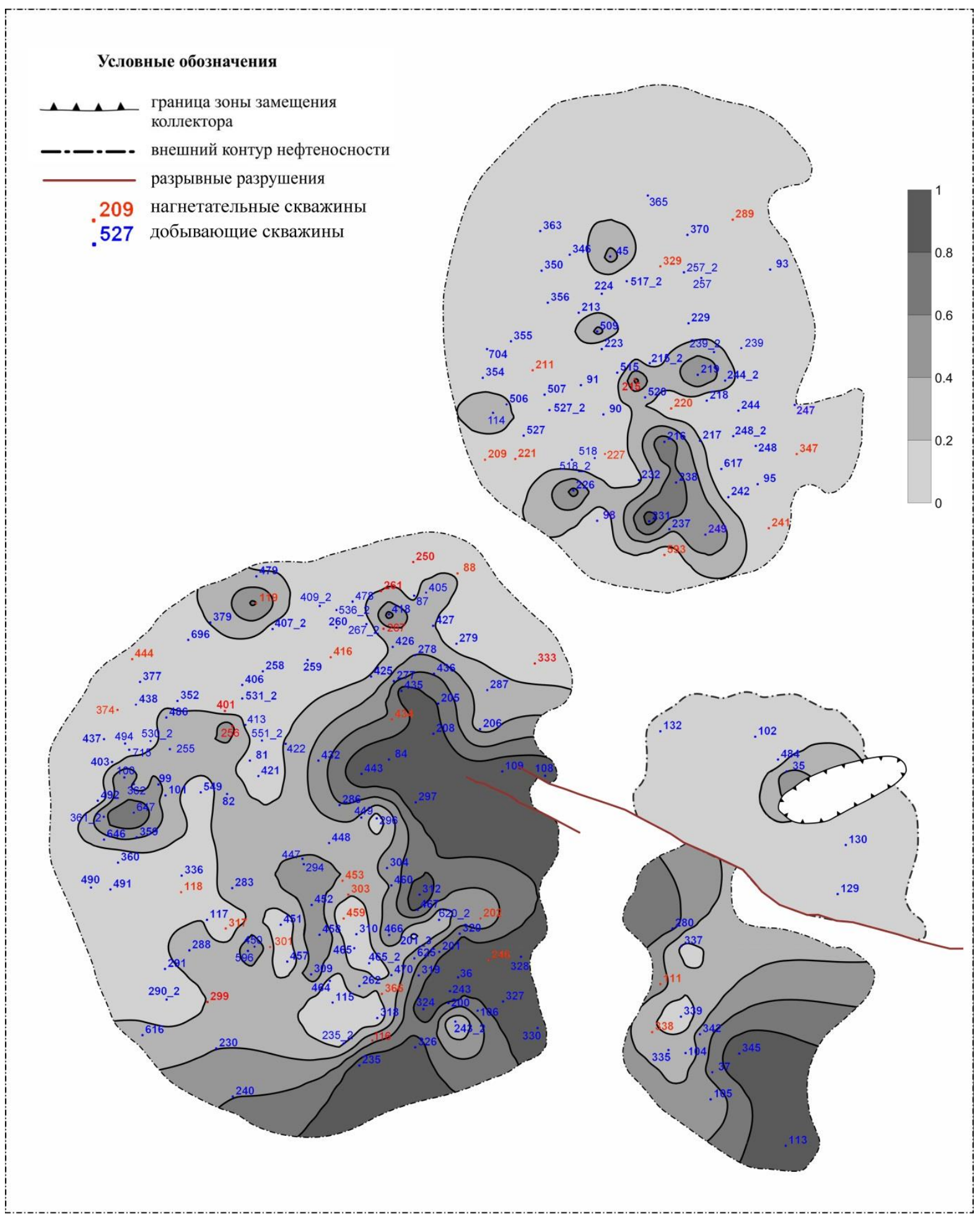

Рис. 3. Схема распространения доли битумизированных коллекторов для эксплуатационного объекта Тл-Бб Уньвинского месторождения

Fig. 3. Scheme of distribution of the share of bituminized reservoirs for the production facility Tl-Bb of the Unvinskoe field

Для Уньвинского поднятия битумизация проявляется наиболее интенсивно в восточной части, где локализуются коллекторы преимущественно с низкой пористостью. Западная и северная часть залежи, напротив, представлены в основном высокопорситыми коллекторами, ввиду чего битумизация там встречена лишь на небольших локальных участках. На Юго-Восточном понятии битумизация установлена в южной и практически отсутствует в северной части. Для Палашерского поднятия в целом битумизация коллекторов не характерна, исключением является локальный участок на юге.

Для однородных по типу смачиваемости участков можно выделить следующие типы геологического разреза по характеру смачиваемости: битуминозный $\left(Д_{\text {фоб }}>0,8\right.$ и Дбит $\left.>0,8\right)$, гидрофобный $\left(Д_{\phi о б}>0,8\right.$ и 
Дбит $<0,8)$, гидрофильный (Д минозный тип коллектора для объекта Тл-Бб в целом прослеживается на востоке Уньвинского поднятия, гидрофобный - на большей части Уньвинского и на северо-западе Палашерского поднятий, гидрофильный - на востоке Палашерского и юге УгоВосточного поднятий.

В целом по площади Уньвинского месторождения установлена высокая степень вертикальной неоднородности коллекторов по типу смачиваемости. Для значительного количества скважин часть коллекторов вскрытого продуктивного разреза может относиться к одному типу, часть - к другому. Поэтому, помимо перечисленных ранее, выделены промежуточные типы: гидрофобно-битуминозный (Д гидрофобно-гидрофильный $\left(0,2<Д_{ф о б}<0,8\right.$ и Дбит $\left.<0,8\right)$. Гидрофобно-битуминозный тип коллектора согласно прогнозной оценке приурочен к участкам, на которых переслаиваются низкопористые битуминозные и высокопористые гидрофобизированные коллекторы. Гидрофобно-гидрофильный тип характерен для коллекторов с высокими ФЕС с чередованием высоко- и низкоомных нефтенасыщенных интервалов. В наименьшей степени на Уньвинском месторождении прогнозируется битуминозно-гидрофильный разрез ввиду того, что в условиях развития преимущественно гидрофильных коллекторов их битумизация маловероятна.

Необходимо заметить, что установленные выше закономерности отражают гидрофобность и битуминозность интервалов коллекторов на макроуровне. Так, согласно общим теоретическим представлениям гидрофобизацию коллекторов принято в большей степени связывать с крупными порами. Вместе с тем в условиях нефтяного пласта для отдельных капилляров смачиваемость может иметь различный характер, что может проявляться даже в единичных образцах керна.

Как видно из диаграмм каротажа на рис. 1, для разрезов скважин характерно переслаивание коллекторов с различными УЭС по БК, что определяет их различную смачиваемость. При этом для гидрофобизированных коллекторов неоднородность геологического разреза будет усилена различной степенью битумизации в зависимости от ФЕС коллекторов. На рис. 2, 3 участки с неоднородностью геологического разреза по степени гидрофобизации Д фоб и битумизации Дбит характеризуются значениями от 0,2 до 0,8 д.е. При этом для некоторых районов возможно равномерное проявление по толщинам битуминозных, гидрофобных и гидрофильных коллекторов, что характеризует еще более сложную для анализа геологическую ситуацию.

\section{Влияние типа смачиваемости и битумизации коллекторов на динамику приемистости нагнетательных скважин}

Смачиваемость коллекторов влияет на динамику работы как добывающих, так и нагнетательных скважин. Для добывающих скважин до начала их обводнения процесс вытеснения нефти из гидрофильных коллекторов происходит в целом более эффективно.
Однако в итоге для гидрофильных коллекторов могут формироваться объемы невытесненной нефти в крупных порах, для гидрофобного пласта конечная выработка нефти из крупных пор выше. Как было указано выше, разработка визейских залежей в Соликамской депрессии идет с заводнением пластов, в результате чего равновесное состояние пластовой системы может быть нарушено с изменением исходного характеpa смачиваемости. Это делает задачу достоверной оценки смачиваемости для нефтяных залежей, разрабатываемых с ППД, особенно актуальной. В целом определение характера влияния смачиваемости коллекторов на продуктивность добывающих скважин является сложной задачей, особенно в условиях высокой неоднородности коллекторов по смачиваемости.

Более определенно негативное влияние гидрофобизации и битумизации коллекторов должно проявляется при анализе эффективности закачки. Опыт разработки визейских объектов показывает, что применение методов интенсификации отборов в ряде случаев не полностью компенсируется закачкой жидкости в пласт. В данной работе выполнен анализ влияния типа смачиваемости коллекторов на динамику коэффициента приемистости (К скважин Уньвинского месторождения. Из рис. 2, 3 видно, что нагнетательные скважины располагаются равномерно на площади всех поднятий и приурочены к различным типам по смачиваемости. В результате учтена информация по работе 36 нагнетательных скважин, для которых были известны $\mathrm{K}_{\text {прием }}$ с начала ввода их в эксплуатацию и в течение последующих 2 лет. Двухлетний период работы скважин задает в целом последующую динамику эксплуатации. На всех скважинах за этот временной период не проводились геолого-технические мероприятия (ГТМ), что позволяет для коллекторов различных типов сопоставить исходные условия эффективности закачки.

На рис. 4 приведены примеры динамики изменения

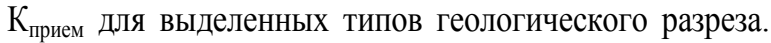
Из представленных примеров видно, что для некоторых скважин приемистость на двухлетнем интервале не достигает эффективных значений $\left(\mathrm{K}_{\text {прием }}<50 \mathrm{~m}^{3} /\right.$ сут $)$

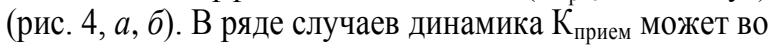
времени иметь разнонаправленный характер. Так, для скважины 119 (рис. 4, в) при начальном значении $K_{\text {прием }}$ более $200 \mathrm{~m}^{3}$ /сут в дальнейшем наступил резкий

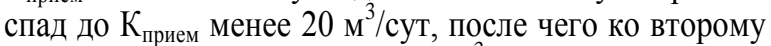
году $\mathrm{K}_{\text {прием }}$ снова превысил $150 \mathrm{~m}^{3} /$ сут. В ряде случаев $\mathrm{K}_{\text {прием }}$ на всем временном интервале имеет стабильно высокие значения $\left(K_{\text {прием }}>200 \mathrm{~m}^{3} /\right.$ сут), что свидетельствует об эффективности закачки без необходимости проведения дополнительных ГТМ (рис. 4, г).

Изменения в динамике приемистости нагнетательных скважин в зависимости от типа коллектора по смачиваемости систематизированы и сведены в таблицу. Для скважины № 246 (восточное крыло Уньвинского поднятия), продуктивная часть которой отнесена исключительно к битуминозному разрезу, значения $\mathrm{K}_{\text {прием }}$ не превышают $50 \mathrm{~m}^{3} /$ сут (рис. 4, a). К гидрофобно-битуминозному типу отнесены шесть скважин, четыре из которых характеризуются $\mathrm{K}_{\text {прием }}$ 
менее $100 \mathrm{~m}^{3} /$ сут. Также невысокая приемистость характерна преимущественно для гидрофобного разреза,

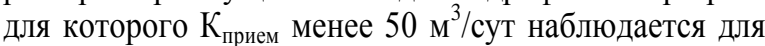
шести скважин. Для гидрофильного типа коллектора, напротив, не установлено примеров работы скважин со стабильно низкой приемистостью $\left(\mathrm{K}_{\text {прием }}<50\right.$

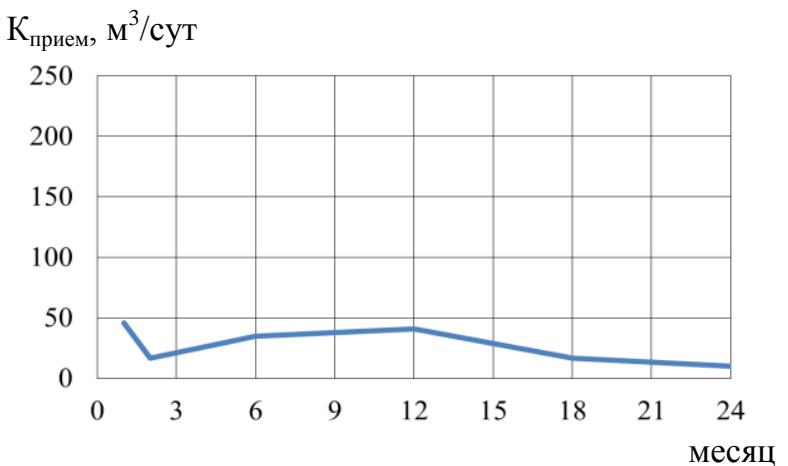

$a / a$

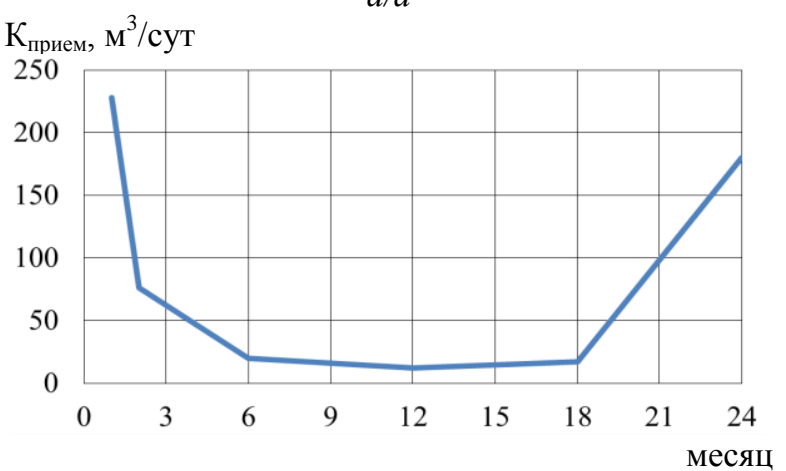

$B / c$
$\mathrm{M}^{3} /$ сут). В целом анализ результатов показывает, что для гидрофобизированного геологического разреза $\mathrm{K}_{\text {прием }}$ ниже, чем в гидрофильных коллекторах, при этом низкая приемистость скважин может являться следствием битумизации или гидрофобизации коллекторов.

$\mathrm{K}_{\text {прием}}, \mathrm{M}^{3} /$ сут

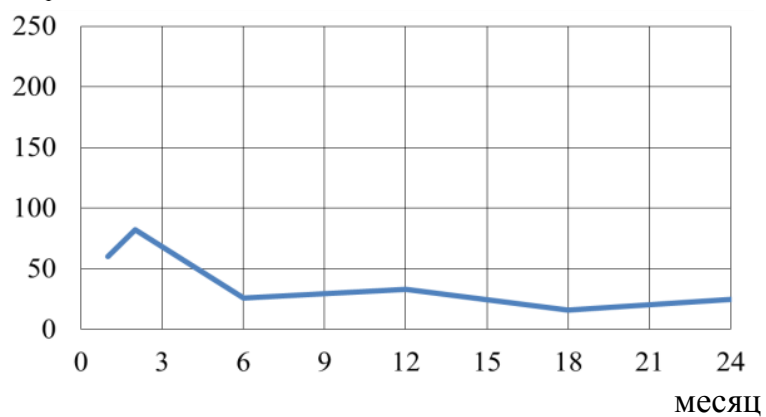

$\sigma / b$

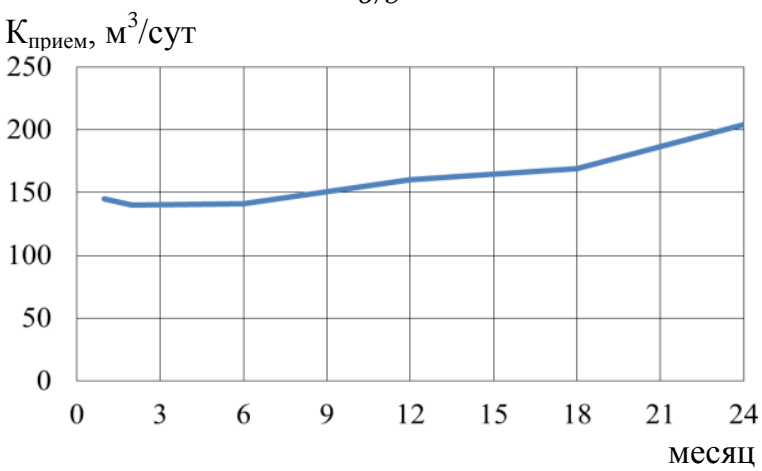

$2 / d$

Pис. 4. Динамика изменения коэффициента приемистости для скважин с различным типом коллектора: а) битуминозный (скважсина № 246); б) гидрофобно-битуминозный (скважина № 119); в) гидрофобно-гидрофильный (скважсина № 301); г) гидрофильный (скважина № 241)

Fig. 4. Dynamics of changes in well injectivity for wells with different types of reservoir: a) bituminous (well № 246); b) bituminous-hydrophobic (well № 119); c) hydrophilic-hydrophobic (well № 301); d) hydrophilic (well № 241)

Таблица. Значения приемистости скважин в зависимости от типа коллектора

Table. $\quad$ Values of well injectivity depending on the type of reservoir

\begin{tabular}{|l|c|c|c|c|c|c|}
\hline \multirow{2}{*}{$\begin{array}{c}\text { тип коллектор } \\
\text { reservoir type }\end{array}$} & $<50$ & $50-100$ & $100-200$ & $>200$ & $\begin{array}{c}\text { без стабилизации } \\
\text { without stabilization }\end{array}$ & $\begin{array}{c}\text { всего } \\
\text { total }\end{array}$ \\
\cline { 2 - 7 } & 1 & 0 & 0 & 0 & 0 & 1 \\
\hline $\begin{array}{l}\text { битуминозный } \\
\text { bituminiferous }\end{array}$ & 2 & 2 & 2 & 0 & 0 & 6 \\
\hline $\begin{array}{l}\text { гидрофобно-битуминозный } \\
\text { hydrophobic-bituminiferous }\end{array}$ & 6 & 0 & 2 & 2 & 4 & 14 \\
\hline $\begin{array}{l}\text { гидрофобный } \\
\text { hydrophobic }\end{array}$ & 1 & 1 & 2 & 2 & 2 & 8 \\
\hline $\begin{array}{l}\text { гидрофобно-гидрофильный } \\
\text { hydrophobic-hydrophilic }\end{array}$ & 0 & 1 & 2 & 1 & 3 & 7 \\
\hline $\begin{array}{l}\text { гидрофильный } \\
\text { hydrophilic }\end{array}$ & 10 & 4 & 8 & 5 & 9 & 36 \\
\hline $\begin{array}{l}\text { всего } \\
\text { total }\end{array}$ & & & & & & \\
\hline
\end{tabular}

Для гидрофобно-гидрофильного разреза получены промежуточные результаты с равномерным присутствуем различных типов динамики изменения $\mathrm{K}_{\text {прием }}$ Анализ работы скважин, относящихся к участкам неоднородного геологического разреза, наиболее затруднен, так как даже относительно невысокая тол- щина работающего гидрофильного коллектора может являться определяющей в текущей динамике закачки скважин. Этим фактором также объяснимо, что для 25 \% скважин (9 из 36) характерны резкие скачки без стабилизации приемистости в течение рассмотренного периода. 


\section{Заключение}

В результате проведенных исследований установлено, что по данным комплексирования методов бокового и микробокового электрического каротажа могут быть выделены площади развития битумизации и гидрофобизации коллекторов. Эксплуатация нагнетательных скважин на таких участках часто характеризуются пониженной приемистостью, что делает стандартное заводнение малоэффективным. Одним из путей оптимизации закачки является создание относительно длинных высокопроводящих каналов, позволяющих увеличить степень охвата пласта процессом вытеснения. Применение для этих целей большеобъемного пропантного гидроразрыва пласта [24-26] в низкопроницаемых битуминозных коллекторах ограничивается высокими экономическими рисками. Кроме этого, для визейских залежей создание высоких давлений разрыва может привести к прорывам флюидов через глинистую перемычку в нижележащие турне-фаменские карбонатные пласты.

Перспективным представляется применение на нагнетательных скважинах менее затратной, чем гидроразрыв, технологии радиального бурения [27-29]. Пока еще ограниченный опыт применения радиального бурения на визейских объектах Соликамской депрессии показал, что в добывающих скважинах наиболее высокий прирост дебитов нефти при значительной длительности эффекта получен для скважин именно с пониженными коллекторскими свойствами [30]. В частности, в результате применения радиального бурения на площади развития битуминозно-

\section{СПИСОК ЛИТЕРАТУРЫ}

1. Михайлов Н.Н., Сечина Л.С., Ермилов О.М. Влияние асфальтенов на смачиваемость газонефтенасыщенных пород коллекторов // Доклады наук о Земле. - 2019. - Т. 486. - № 1. C. $465-467$.

2. Михайлов Н.Н., Ермилов О.М. Михайлов А.Н. Капиллярные граничные эффекты в резервуарах с гетерогенной смачиваемостью // Доклады наук о Земле. - 2020. - Т. 494. - № 1. C. 680-683.

3. Особенности изучения смачиваемости сложнопостроенных карбонатных пород-коллекторов лабораторными методами / И.П. Гурбатова, С.В. Мелехин, Д.В. Чижов, Ю.В. Файрузова // Вестник Пермского национального исследовательского политехнического университета. Геология. Нефтегазовое и горное дело. - 2016. - T. 15. - № 20. - С. 240-245. DOI: $10.15593 / 2224-9923 / 2016.20 .4$

4. Исследование гранулометрического состава битуминозных песчаников Ашальчинского месторождения методом рентгеновской микротомографии / Т.Р. Закиров, А.А. Галеев, Н.И. Жаркова, Е.О. Стаценко, Э.А. Королев, Л.И. Хайдарова // Нефтяное хозяйство. - 2016. - № 10. - С. 35-37.

5. Fracture evolution mechanism of hollow sandstone under conventional triaxial compression by X-ray micro-CT observations and three-dimensional numerical simulations / S. Yang, Z. Yang, H. Jing, T. Xu // International Journal of Solids and Structures. 2020. - V. 190. - P. 156-180.

6. Estimation of heterogeneity of oil \& gas field carbonate reservoirs by means of computer simulation of core X-ray tomography data / A.A. Efimov, S.V. Galkin, Ia.V. Savitckii, V.I. Galkin // Ecology. Environment and Conservation. - 2015. - V. 21. - P. 79-85.

7. Workflow for upscaling wettability from the nanoscale to core scale / M. Rucker, W. Bartels, T. Bultreys, M. Boone, K. Singh G. Garfi, A. Scanziani, C. Spurin, S. Yesufu-Rufai, S. Krevor, M.J. Blunt, O. Wilson // Petrophysics. - 2020. - V. 61. - № 2. P. 189-205. гидрофобных коллекторов (скважина на юге ЮгоВосточного поднятия) прирост дебита по нефти составил 24 т/с, что более чем в 3 раза превышает стандартную эффективность.

В части поиска химических технологий повышения приемистости коллекторов гидрофобнобитуминозного типа целесообразно проведение опытно-промышленных работ по гидрофилизации пластов, например, с помощью применения поверхностно активных веществ. Дополнительный эффект вытеснения остаточной нефти при этом может быть получен за счет уменьшения капиллярных сил. Согласно мировой практике в условиях гидрофобных и малоглинистых песчаников для этих целей в качестве перспективной технологии может рассматриваться щелочное заводнение, которое в том числе ранее имело ограниченное применение на месторождениях Пермского региона [31]. Адсорбируясь на поверхности коллекторов, щелочь, помимо увеличения подвижности нефти, также снижает смачиваемость, что приводит к удалению из породы плохо растворимых веществ. Таким образом, для выявленных по данным каротажа зон развития гидрофобно-битуминозных коллекторов можно рекомендовать ряд перспективных технологий воздействия на пласт на основе физических и химических методов.

Исследование выполнено в рамках государственного задания Минобрнауки РФ FSNM-2020-0027 на выполнение фундаментальных научных исследований на 2020 г. и плановый период 2021 и 2022 г2.

8. Козырев Н.Д., Вишняков А.Ю., Путилов И.С. Оценка влияния параметров неопределенности на прогнозирование показателей разработки // Недропользование. - 2020. - Т. 20. - № 4. C. $356-368$. DOI: $10.15593 / 2712-8008 / 2020.4 .5$

9. Уточнение геолого-гидродинамической модели сложнопостроенной залежи нефти путем комплексного анализа данных / Н.Д. Козырев, А.А. Кочнев, А.Г. Менгалиев, И.С. Путилов, С.Н. Кривощеков // Известия Томского политехнического университета. Инжиниринг георесурсов. - 2020. - Т. 331. № 10. - C. 164-177. DOI: 10.18799/24131830/2020/10/2866

10. Менгалиев А.Г., Мартюшев Д.А. Учет параметра анизотропии проницаемости в геолого-гидродинамических моделях карбонатных объектов (на примере Гагаринского месторождения) // Известия Томского политехнического университета. Инжиниринг георесурсов. - 2020. - Т. 331. - № 5. - С. 7-17. DOI: $10.18799 / 24131830 / 2020 / 5 / 2632$

11. Сахибгареев Р.С. Вторичные изменения коллекторов в процессе формирования и разрушения нефтяных залежей. - Л.: Недра, 1989. - 260 с

12. Геохимические особенности и условия образования битумов в нефтяных залежах (на примере месторождений Татарстана) / Т.Н. Юсупова, Ю.М. Ганеева, Л.М. Петрова, Р.З. Мухаметшин, А.А. Галеев // Геология нефти и газа. - 2009. - № 2. - С. 52-59.

13. Dual neural network architecture for determining permeability and associated uncertainty / R. Kausik, A. Prado, V.-M. Gkortsas, L. Venkataramanan, H. Datir, Y.B. Johansen // Petrophysics. 2021. - V. 62. - № 1. - P. 122-134.

14. Iskenderov M. Some results of modeling electrical resistivity (on the example of deposits of the South-Absheron aquatorium zone and the northern part of the Baku archipelago) // SOCAR Proceedings. - 2017. - V. 2. - № 2. - P. 4-12. DOI: 10.5510/OGP20170200310

15. Garcia A.P., Heidari Z., Rostami A. Improved assessment of hydrocarbon saturation in mixed-wet rocks with complex pore structure // Petrophysics. - 2017. - V. 58. - № 5. - P. 454-469. 
16. Мухаметшин Р.3., Галеев А.А. Диагностика древних водонефтяных контактов инструментальными методами // Нефтяное хозяйство. - 2014. - № 10. - С. 28-33.

17. Study of wettability of reservoirs of oil fields by the method of $\mathrm{x}$ ray tomography core / A. Efimov, Ya. Savitskiy, S. Galkin E. Soboleva, V. Gurbanov // SOCAR Proceedings. - 2016. - V. 4 - № 4. - P. 55-63. DOI: 10.5510/OGP20160400298

18. Геологические факторы и диагностические признаки пород с негидрофильной смачиваемостью на месторождениях Тимано-печорской провинции / Т.Ф. Дьяконова, Л.К. Бата, А.Д. Саетгараев, Е.И. Бронскова // Каротажник. - 2021. Т. 307. - № 1. - С. 19-30.

19. Опыт применения метода многозондового бокового каротажа / О.Л. Сальникова, А.В. Серкина, А.Д. Савич, А.С. Чухлов // Каротажник. - 2019. - Т. 299. - № 5. - С. 55-61.

20. Проявления и пути уменьшения влияния на показания приборов бокового электрического каротажа некоторых нежелательных эффектов / В.А. Клименко, Л.А. Книжнерман, В.М. Коровин, Т.Р. Салахов, М.Д. Хусид // Геофизика. 2019. - № 3. - С. 54-59.

21. Клименко В.А., Салахов Т.Р. Опыт применения прибора пятизондового бокового каротажа высокого разрешения, сложная интерпретация // Геофизика. - 2018. - № 2. - С. 68-76.

22. Галкин С.В., Колычев И.Ю., Савицкий Я.В. Возможности исследования гидрофобизации коллекторов комплексированием методами рентгеновской томографии керна и электрического каротажа // Геология и геофизика. - 2019. - № 10. - С. 1496-1507. DOI: $10.15372 / \mathrm{GiG} 2019094$

23. Сметкина М.А., Мелкишев О.А., Присяжнюк М.А. Уточнение значений проницаемости при адаптации гидродинамической модели // Недропользование. - 2020. - Т. 20. - № 3. - С. 223-230. DOI: $10.15593 / 2712-8008 / 2020.3 .3$

24. Patel S., Sondergeld C., Rai C. Laboratory studies of hydraulic fracturing by cyclic injection // International Journal of Rock Mechanics and Mining Sciences. - 2017. - V. 95. - P. 8-15.
25. Yuan J., Jiang R., Zhang W. The workflow to analyze hydraulic fracture effect on hydraulic fractured horizontal well production in composite formation system // Advances in GeoEnergy Research. - 2018. - V. 2. - № 3. - P. 319-342.

26. An environment friendly approach to reduce the breakdown pressure of high strength unconventional rocks by cyclic hydraulic fracturing / Z. Tariq, M. Mahmoud, A. Abdulraheem, D. Al-Shehri, M. Murtaza // Journal of Energy Resources Technology. - 2020. V. 142. - № 4. - Article 043002.

27. Insights into the radial water jet drilling technology - application in a quarry / T. Reinsch, B. Paap, S. Hahn, V. Wittig, S. van den Berg // Journal of Rock Mechanics and Geotechnical Engineering. - 2018. - V. 10. - Iss. 2. - P. 236-248.

28. Application of machine learning algorithms to predict the effectiveness of radial jet drilling technology in various geological conditions / A. Kochnev, S. Galkin, S. Krivoshchekov, N. Kozyrev, P. Chalova // Applied Sciences (Switzerland). - 2021. V. 11. - Article 4487. DOI: 10.3390/app11104487.

29. Maximum drillable length of the radial horizontal micro-hole drilled with multiple high-pressure water jets / H. Chi, G. Li, Z. Huang, S. Tian, X. Song // Journal of Natural Gas Science and Engineering. - 2015. - V. 26. - P. 1042-1049.

30. Кочнев А.А., Зотиков В.И., Галкин С.В. Анализ влияния геолого-технологических показателей на эффективность технологии радиального бурения на примере эксплуатационных объектов Пермского края // Известия Томского политехнического университета. Инжиниринг георесурсов. - 2018. T. 329. - № 12. - C. 20-29. DOI: 10.18799/24131830/2018/12/16

31. Оценка результатов щелочного заводнения в Пермском крае / И.Р. Юшков, А.А. Ерофеев, А.И. Юшков, А.А. Злобин // Нефтепромысловое дело. - 2013. - № 9. - С. 57-63.

Поступила 01.12.2021 2.

\section{Информация об авторах}

Галкин С.B., доктор геолого-минералогических наук, профессор, декан горно-нефтяного факультета Пермского национального исследовательского политехнического университета.

Колычев И.Ю., кандидат технических наук, научный сотрудник кафедры нефтегазовых технологий Пермского национального исследовательского политехнического университета.

Ракинцев В.A., инженер в области мониторинга и проектирования разработки нефтяных и газовых месторождений, филиал ООО «ЛУКОЙЛ-Инжиниринг» «ПермНИПИнефть» в г. Перми. 


\title{
UDC 552.086 \\ POSSIBILITIES OF DETERMINING THE TYPE OF WETTABILITY OF THE COLLECTORS BY LOGGING DATA WHEN OPTIMIZING THE SYSTEM OF FLOODING OF OIL RESERVOIRS
}

\author{
Sergey V. Galkin', \\ doc_galkin@mail.ru \\ Igor Yu. Kolychev', \\ igorek999@yandex.ru \\ Vladimir A. Rakintsev ${ }^{3}$, \\ rakintsevv.a@mail.ru \\ 1 Perm National Research Polytechnic University, \\ 29, Komsomolsky avenue, Perm, 614990, Russia. \\ 2 Branch of LLC LUKOIL-Engineering «PermNIPIneft» in Perm, \\ 3a, Permskaya street, Perm, 614015, Russia.
}

The relevance. The wettability of oil-saturated reservoirs significantly affects the technological features of the development of production facilities, primarily the efficiency of waterflooding of oil reservoirs. Possibilities of determining the wettability of reservoirs based on the data of geophysical studies of wells make it possible to take this indicator into account in geological and technological modeling of the development of oil fields, including when optimizing waterflooding of oil reservoirs. This problem was solved for the conditions of terrigenous oil-saturated reservoirs, for which it is based on the integration of reservoir porosity, lateral electrical logging and micro-lateral logging. The publication presents the results and analysis of the dynamics of injectivity of injection wells in the conditions of the development of bituminous, hydrophobized and hydrophilic reservoirs. For areas with low injectivity of wells, geological and technical measures were proposed to optimize the waterflooding system for oil reservoirs.

Object: oil-saturated reservoirs of the Visean oil deposits of the Solikamsk depression (Perm region).

Method: development of a methodology and determination of the type of wettability and the degree of bitumization of terrigenous reservoirs based on the data of gamma-ray logging, lateral electric logging and micro-side logging; analysis of the dynamics of injectivity of injection wells for various identified types of wettability.

Results. Based on the developed methodology, the authors have obtained zoning schemes for development of hydrophobization and bituminization of oil-saturated reservoirs for the TI-Bb object of the Unvinskoe field. The analysis of the dynamics of the operation of injection wells for the conditions of a bituminous, hydrophobized and hydrophilic geological section is carried out. The schemes of zoning of development of hydrophobization and bitumization processes of reservoirs, which are associated with areas of decreased injectivity of injection wells, were constructed. Geological and technical measures are proposed to optimize the waterflooding system for oil reservoirs in hydrophobic-bituminous reservoirs.

\section{Key words:}

Wettability, hydrophobic reservoir, bituminization, well logging, specific electrical resistance, lateral logging, flooding of oil reservoirs.

The study was carried out within the framework of the state task of the Ministry of Science and Higher Education of Russian Federation FSNM-2020-0027 for the implementation of fundamental scientific research.

\section{REFERENCES}

1. Mikhailov N.N., Sechina L.S., Ermilov O.M. Effect of asphaltenes on wettability of gas and oil saturated reservoir rocks. Doklady Earth Sciences, 2019, vol. 486, no. 1, pp. 465-467. In Rus.

2. Mikhailov N.N., Ermilov O.M., Mikhailov A.N. Capillary end effects in reservoirs with heterogeneous wettability. Doklady Earth Sciences, 2020, vol. 494, no. 1, pp. 680-683. In Rus.

3. Gurbatova I.P., Melekhin S.V., Chizhov D.B., Fairuzova Yu.V Features of study complex carbonate reservoir rocks' wetting using laboratory methods. Bulletin of Perm National Research Polytechnic University. Geology. Oil \& Gas Engineering \& Mining, 2016, vol. 15, no. 20, pp. 240-245. In Rus.

4. Zakirov T.R., Galeev A.A., Zharkova N., Statsenko E.O. Korolev E.A., Khaidarova L.I. X-ray microtomography and grain size analysis of bituminous sandstones from ashalchinskoye oil field. Oil industry, 2016, no. 10, pp. 35-37. In Rus.

5. Yang S., Yang Z., Jing H., Xu T. Fracture evolution mechanism of hollow sandstone under conventional triaxial compression by $\mathrm{X}$-ray micro-CT observations and three-dimensional numerical simulations. International Journal of Solids and Structures, 2020, vol. 190, pp. 156-180.
6. Efimov A.A., Galkin S.V., Savitckii Ia.V., Galkin V.I. Estimation of heterogeneity of oil \& gas field carbonate reservoirs by means of computer simulation of core x-ray tomography data. Ecology. Environment and Conservation, 2015, vol. 21, pp. 79-85.

7. Rucker M., Bartels W., Bultreys T., Boone M., Singh K., Garfi G., Scanziani A., Spurin C., Yesufu-Rufai S., Krevor S., Blunt M.J., Wilson O. Workflow for upscaling wettability from the nanoscale to core scale. Petrophysics, 2020, vol. 61, no. 2, pp. 189-205.

8. Kozyrev N.D., Vishnyakov A.Yu., Putilov I.S. Assessment of the uncertainty parameters influence on the development indicators forecasting. Perm Journal of Petroleum and Mining Engineering, 2020, vol. 20, no. 4, pp. 356-368. In Rus.

9. Kozyrev N.D., Kochnev A.A., Mengaliev A.G., Putilov I.S., Krivoshchekov S.N. Refinement of the geological and hydrodynamic model of a complex oil reservoir by means of a comprehensive data analysis. Bulletin of the Tomsk Polytechnic University. Geo Assets Engineering, 2020, vol. 10, no. 331, pp. 164-177. In Rus.

10. Mengaliev A.G., Martyushev D.A. Accounting the parameter of anisotropy of permeability in geological and hydrodynamic models of carbonate objects (On the example of the Gagarin deposit). Bulletin of the Tomsk Polytechnic University. Geo Assets Engineering, 2020, vol. 5, no. 331, pp. 7-17. In Rus. 
11. Sakhibgareev R.S. Vtorichnye izmeneniya kollektorov v protsesse formirovaniya $i$ razrusheniya neftyanykh zalezhey [Secondary reservoir changes in the process of formation and destruction of oil deposits]. Leningrad, Nedra Publ., 1989. 260 p.

12. Yusupova T.N., Ganeeva Yu.M., Petrova L.M., Mukhametshin R.Z., Galeev A.A. Geochemical features and formation conditions of bitumen in oil pools (with reference to tatarstan's fields). Geologiya Nefti i Gaza, 2009, no. 2, pp. 52-59. In Rus.

13. Kausik R., Prado A., Gkortsas V.-M., Venkataramanan L., Datir H., Johansen Y.B. Dual neural network architecture for determining permeability and associated uncertainty. Petrophysics, 2021, vol. 62, no. 1, pp. 122-134.

14. Iskenderov M. Some results of modeling electrical resistivity (on the example of deposits of the South-Absheron aquatorium zone and the northern part of the Baku archipelago). SOCAR Proceedings, 2017, vol. 2, no. 2, pp. 4-12.

15. Garcia A.P., Heidari Z., Rostami A. Improved assessment of hydrocarbon saturation in mixed-wet rocks with complex pore structure. Petrophysics, 2017, vol. 58, no. 5, pp. 454-469.

16. Mukhametshin R.Z., Galeev A.A. Diagnostics of ancient oil-water contacts by instrumental methods. Oil industry, 2014, no. 10, pp. 28-33. In Rus.

17. Efimov A., Savitskiy Ya., Galkin S., Soboleva E., Gurbanov V. Study of wettability of reservoirs of oil fields by the method of $\mathrm{X}$-ray tomography core. SOCAR Proceedings, 2016, vol. 4, no. 4 , pp. 55-63.

18. Diakonova T.F., Bata L.K., Saetgaraev A.D., Bronskova E.I. Geological factors and diagnostic signs of non-water-wetting rocks in Timan-pechora province fields. Well Logger, 2021, vol. 307 , no. 1, pp. 19-30. In Rus.

19. Salnikova O.L., Serkina A.V., Savich A.D., Chukhiov A.S. An experience of applying the method of multisonde lateral logging. Well Logger, 2019, vol. 299, no. 5, pp. 55-61. In Rus.

20. Klimenko V.A., Knizhnerman L.A., Korovin V.M., Salahov T.R., Khusid M.D. Manifestation and methods of reduction of some unwanted effects on the laterolog tools' well-logging curves. Geofizika, 2019, no. 3, pp. 54-59. In Rus.

21. Klimenko V.A. Salahov T.R. Experience of the high resolution five-sondes laterolog tool, complex interpretation. Geofizika, 2018, no. 2, pp. 46-51. In Rus.

22. Galkin S.V., Kolychev I.J., Savitskiy Ya.V. Potentialities of investigation of reservoir hydrophobization by compilation of
X-ray core tomography and lateral logging. Russian Geology and Geophysics, 2019, no. 10, pp. 1496-1507. In Rus.

23. Smetkina M.A., Melkishev O.A., Prisyazhnyuk M.A. Refining the values of permeability when adapting the hydrodynamic model. Perm Journal of Petroleum and Mining Engineering, 2020, vol. 20, no. 3, pp. 223-230. In Rus.

24. Patel S., Sondergeld C., Rai C. Laboratory studies of hydraulic fracturing by cyclic injection. International Journal of Rock Mechanics and Mining Sciences, 2017, vol. 95, pp. 8-15.

25. Yuan J., Jiang R., Zhang W. The workflow to analyze hydraulic fracture effect on hydraulic fractured horizontal well production in composite formation system. Advances in GeoEnergy Research, 2018, vol. 2, no. 3, pp. 319-342.

26. Tariq Z., Mahmoud M., Abdulraheem A., Al-Shehri D., Murtaza M. An environment friendly approach to reduce the breakdown pressure of high strength unconventional rocks by cyclic hydraulic fracturing. Journal of Energy Resources Technology, 2020, vol. 142 , no. 4 , article 043002 .

27. Reinsch T., Paap B., Hahn S., Wittig V., van den Berg S. Insights into the radial water jet drilling technology - application in a quarry. Journal of Rock Mechanics and Geotechnical Engineering, 2018, vol. 10, Iss. 2, pp. 236-248.

28. Kochnev A., Galkin S., Krivoshchekov S., Kozyrev N., Chalova P. Application of machine learning algorithms to predict the effectiveness of radial jet drilling technology in various geological conditions. Applied Sciences (Switzerland), 2021, vol. 11, article 4487.

29. Chi H., Li G., Huang Z., Tian S., Song X. Maximum drillable length of the radial horizontal micro-hole drilled with multiple high-pressure water jets. Journal of Natural Gas Science and Engineering, 2015, vol. 26, pp. 1042-1049.

30. Kochnev A.A., Zotikov V.I., Galkin S.V. Analysis of the influence of geological technological parameters on the effectiveness of radial drilling technology on the example of operational objects in perm region. Bulletin of the Tomsk Polytechnic University. Geo Assets Engineering, 2018, vol. 329, no. 12, pp. 20-29. In Rus.

31. Yushkov I.R., Erofeev A.A., Yushkov A.I., Zlobin A.A. Evaluation of results of alkaline flooding in perm region. Oilfield engineering, 2013, no. 9, pp. 57-63. In Rus.

Received: 1 December 2021.

\section{Information about the authors}

Sergey V. Galkin, Dr. Sc., professor, dean of the Mining-Oil Faculty, Perm National Research Polytechnic University. Igor Yu. Kolychev, Cand. Sc., researcher, Perm National Research Polytechnic University.

Vladimir A. Rakintsev, engineer in the field of monitoring and design of oil and gas fields development, branch of LLC LUKOIL-Engineering «PermNIPIneft» in Perm. 